\title{
ULCERATING GRANULOMA OF THE PUDENDA
}

A REVIEW OF THE LITERATURE WITH A BIBLIOGRAPHy AND SOME OBSERVATIONS OF THE DISEASE AS SEEN IN PCRTO RICO

\author{
HERMAN GOODMAN, B.S., M.D. \\ Formerly Venereal Officer, Camp Las Casas, Porto Rico \\ NEW YORK
}

\section{INTRODUCTION}

Ulcerating granuloma of the pudenda is a skin and mucous membrane disease found in the tropics. It is an infectious, chronic, indurated, cicatrizing growth on or near the genitals of both male and female, with no tendency to glandular involvement or serious impairment of the general health.

The increasing migrations between continental United States and Porto Rico, with the possibility of transferring the infection, is deemed to be of sufficient importance to warrant the reporting of the first cases diagnosed on our insular possession.

The available literature has been studied, and only one reference has been found to the disease in any part of the United States or its tropical dependencies. Lieutenant Pederson, U. S. Navy, had three cases in St. Thomas, V. I. (personal communication), and Dr. Gehringer had one in Panama (personal communication). From our island neighbor, Cuba, report of two cases has been made by Pardo of Havana.

Ulcerating granuloma of the pudenda is briefly mentioned in many of the modern dermatologic textbooks. The volumes on tropical medicine and pathology in English, French, Spanish and Portugese at our disposal give brief space to the disease, and the journals of late years have original articles and abstracts of reports.

Synonyms.-Ulcerating granuloma of the pudenda is the name most often applied to the disease. This name implies the pathologic process of granuloma with subsequent ulceration. A name which emphasizes another pathologic process is sclerotisizing or sclerosing granuloma of the pudenda. Serpiginous ulcerations of the genitalia was the term applied by McLeod. Granuloma inguinale tropicum, granuloma venerum, groin ulceration, and chronic venereal sores have all been used. Da Matta proposes the term "granulomatoses" for this group of cases 
History.-Ulcerating granuloma of the pudenda was buried among the nondescript "tropical ulcers" until recognized as a clinical entity by Conyers and Daniels in 1896. They observed the disease in British Guiana. Since that time, cases have been reported and studies made on the etiology, pathology and treatment of the disease.

Geographical Distribution.-British Guiana, Dutch Guiana, Brazil, Uruguay, Argentine and the West Indies have the disease. The same or a similar disease exists in the Fiji Islands, India, East Indies, Northern Australia, the west coast of Africa and South China. Rarely, has an identical disease been encountered in Europe. Grindon reported three cases in the United States. In our own field of study, Porto Rico, we have seen four cases. It seems probable that many more cases are to be encountered on the island.

Age of Patients.-The majority of the patients are in the period of sexual maturity. Rarely has the disease been acquired by children, or by those over 45 years of age.

Sex Affected. - Manson states that males are less frequently affected than females.

Color-A theory as to the predisposition on the part of the colored races has been advanced; but reports of the disease among whites are sufficiently common to warrant the statement that race plays no essential part in the etiology of the disease.

\section{IIJSTOPATIIOLOGY}

The histopathologic study made by Galloway on material furnished by Daniels has been most often quoted and paraphrased. According to the researches of this author:

The microscopic changes commence at some distance from the points where the disease becomes visible to the naked eye. The lesion consists of a round cell infiltration appearing in the upper regions of the corium which extends upward into the papillae and also to a variable extent downward into the subcutaneous tissue. The main mass of the exudation, however, lies in the upper layer of the cutis, and in the papillae themselves. As the amount of this exudation increases, the papillae increase in size, both in length and breadth, and the interpapillary processes of the epidermis become elongated, so that they may attain to eight or ten times the usual length. As the result of these changes, a very complicated arrangement of columns of epithelial cells and dense exudation of rounded cells of mesoblastic origin forms the characteristic appearance of the growth in its most active state.

The connective tissue of the corium disappears under the influence of the infiltration, its fibrils become swollen, refuse to take the ordinary connective tissue pigments and at length vanish. As the connective tissue is destroyed its place is taken by the new infiltration, so that dense masses of the new growth underlie the elongated interpapillary processes of epithelium. In these 
masses only a few irregular trabeculae of connective tissue can be distinguished, and these are frequently in a degenerate condition.

The elastic tissue may also be observed to undergo changes of a distinctive character. The regular arrangement of the fibers, which can readily be seen where the skin is still normal, hecomes disturled on the advance of the infiltration. The individual fibers become swollen and at length broken up into short lengths. As the dense areas of infiltration are reached, the main elastic fibers in the corium are so altered in their arrangement that, instead of coursing in a direction more or less parallel with the surface of the skin, fragments of them may he seen in connective tissue traheculae lying in all directions, even at right angles to the surface of the cutis. In the infiltration itself all traces of elastic tissue disappear. The elastic filers of the papillae and in other parts are destroyed in a similar manner.

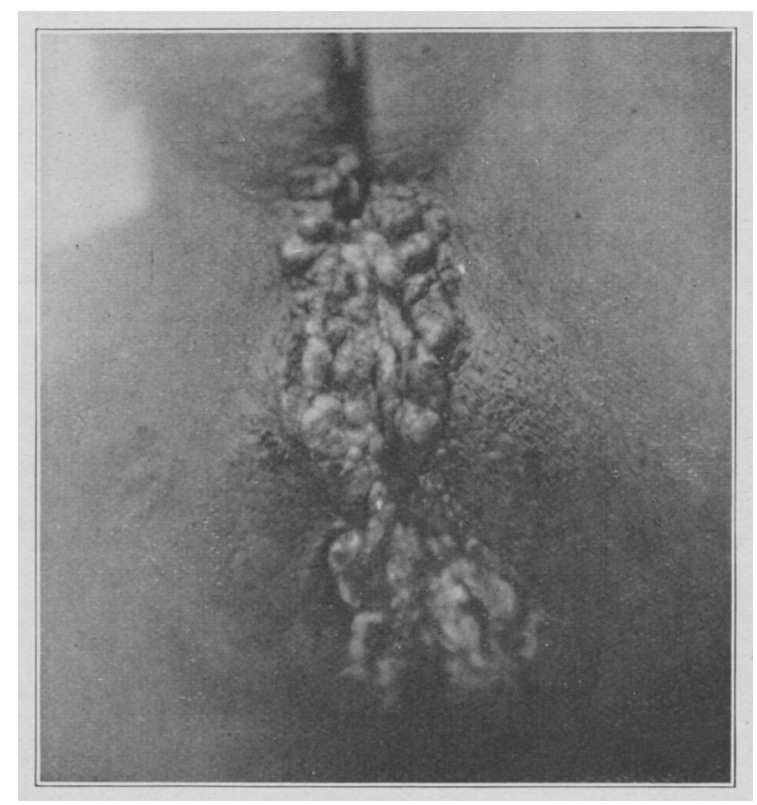

Fig. 1 (Case 1). Pea-sized papillomas between commissure of the vulva, including perineal space, and circumscriling the anus. The disease process passed into the vagina and into the rectum.

It is noteworthy that no tendency to caseation or to suppuration is observed in the masses of infiltration. In the older parts of the growth, the newly formed cells become swollen, disappear and the situation of the infiltration becomes occupied by newly formed bands of connective tissue, distinguished from those originally existing by their straight instead of wavy course and by the density of their arrangement. Shrinking takes place in the size of the tumor, and firm scar tissue is formed.

As the infiltration appears in the papillae the cells of the rete malpighii in the interpapillary processes of the epithelium become swollen, their protoplasm becomes more hyaline in appearance and clivision of the nuclei and cells appears to take place, although mitoses are uncommon, so as to permit the 
necessary increase of the interpapillary processes. The increase of the infiltration raises the corium in the form of a small tumor, and the epithelium becomes stretched over it. This additional alteration conduces still more to disturbance of the epithelial cells. There is interference with the regular columnar arrangement of the lowest layer of cells in the stratum mucosum. The cells are elongated and are less distinguishable from the overlying cells of the prickle layers. Leukocytes make their way into the altered epithelium from the underlying infiltration and wander through the lymph channels of the epithelium, which becomes peculiarly olovious. As the summit of the little tumors is approached, the epithelium becomes more and more infiltrated with leukocytes, and at the most prominent part, a thin crust of leukocytes, epithelial and leukocytic débris may le frequently distinguished. The epithelial layers below are full of leukocytes and the lymph spaces contain, besides leukocytes of various shapes, the relics of leukocytes and possibly of epithelial cells, free from chromatin granules.

In spite of the stretching and thinning of the epithelium and its infiltration with the leukocytes, complete disappearance of the suprapapillary epidermis appears to be uncommon; but in some specimens a deep ulcer is seen to have formed with complete destruction of the epithelium and the appearance of dense scar tissue. This characteristic, it will be noticed, corresponds to one of the important clinical features of the case.

The stratum grantilosum undergoes great alteration. In the neighlooring normal skin it is readily observed, as is also the overlying stratum corneum. As the area of disease is reached,. the cells fail to develop the granules of keratohyaline regularly, and at a point ahout half way toward the summit of the tumor the cells of the stratum granulosum have quite vanished. A similar fate attends the cells of the stratum corneum. The epithelium overiying the upper parts of the tumor, therefore, is formed of cells of very nearly the same appearance, without pigment and without the normal granules of keratolyaline and without undergoing the regular formation of horny material. The upper cells differ only in shape, and very little in staining reactions from the epithelial cells immediately in contact with the transformed corium.

Conyers and Daniels give a detailed account of the microscopic structure of either the smallest nodules or larger masses as showing:

The mass of nodules are composed of round cells, with a large (but usually badly staining) nucleus, contained in a clelicate reticulum of filbrous tissue. This mass is covered by epithelium in its greater extent and in the older and larger nodules merges gradually into a subjacent dense filbrous stroma in which small masses of similar rounded cells are emledded. The growths are very vascular and the capillaries are much dilated, but there are no hemorrhages. There is no sign of suppuration or caseation, and no giant cells are found in any of the sections. The overlying epithelium has undergone certain modifications; it is usually intact; or cracked and, occasionally over small areas, alssent or ill formed, and the cells of the rete malpighii are ill defined and swollen. None of the pigment so characteristic of the colored race is found in the deeper layers. In many specimens there is a proliferation of the interpapillary epithelium. in some. sufficient for columns of epithelial cells to appear to descend into the round celled growth. In others. on the other hand, the papillae have almost disappeared from a more wide- 
spread proliferation of the epithelium. The hair follicles in many cases share the epidermic thickening, and the hairs grow strongly and are not changed in color. In a section of a small nodule, the round cell mass will be found to be roughly wedge-shaped, the base of the wedge being toward the skin, the growth ascending with the vessels into the papillae.

\section{ETIOLOGY}

There has been some difference of opinion as to the bacterial agent of ulcerating granuloma. Different investigators have described dif..

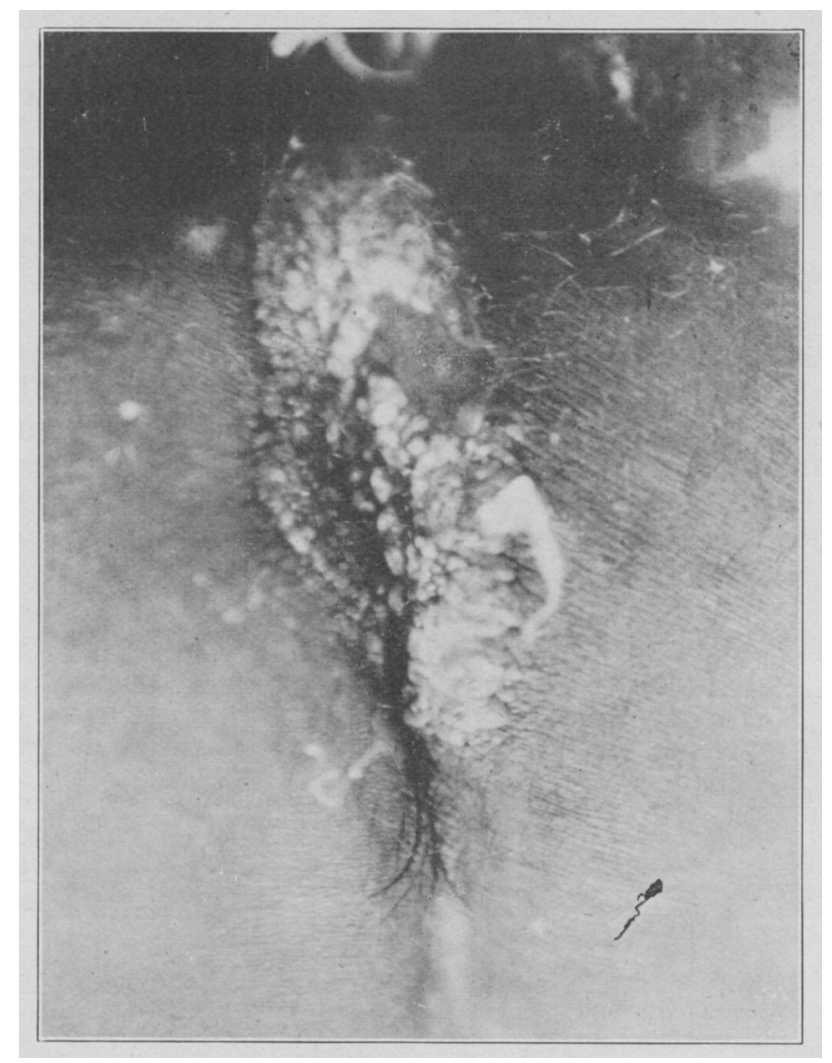

Irig. 2 (Case 2).-The condylomatous type of the disease, covered by slough. Individual papules, varying in size up to that of an almond, were present.

ferent organisms, and there has been confirmatory evidence accumulating for the two main contenders, namely, IIise, who advanced the theory of spirochetal origin, and Donovan, who advanced the theory of Calimatobacterinm granulomatis origin.

Wise reported in 1906 and 1907, that he had found in the eruption spirochetes resembling $S$. refringchs and $S$. pallida but they were not exactly similar. Cleveland confirmed Wise's observations on the spirochete and has called 
it $S$. aboriginalis. MacLennan found the spirochete of ulcerating granuloma more delicate, more closely waved, very much longer, and more difficult to stain than $S$. pallida.

Donovan has described small rod or coccus-like bodies, two microns by one micron, which lie singly or in groups in mononuclear cells obtained by scraping the sores. His results have been confirmed and enlarged by Siebert and later, by Flu. De Beaurefaire Araga and Vianna have cultivated the capsulated coccus-like bodies described by the above authoritics. Cultivation has been obtained also by Martini.

Manson calls the parasite a "gigantic short bacillus with rounded ends occurring in large mononuclear cells and in great profusion. The parasites are sometimes scattered irregularly through the protoplasm of the affected cells, more often they are arranged in little round clusters of eight or ten. On deep staining, something like an elongated nucleus can be made out." According to Manson, the position this organism occupies and its peculiar characteristics are highly suggestive of its being the cause of the disease.

Calimatobacterium granulomatis, according to de Souza Araujo, when stained by the method of Gram, whether in smears, in section or from culture, takes the stain; but the capsule remains unstained. The method of choice for the organism is that of Giemsa, by which there is presented a characteristic appearance. The body of the organism takes an intense violet color, and the capsule appears pink, sometimes dark red, with small clear spaces. When deeply stained, extracellular forms at times present the appearance of cocci, stained dark violet and surrounded by a capsule. This form is about 0.2 or 0.3 microns and with its capsule about 1 or 1.5 microns. In gencral, the capsule is oval and the microbe appears elongated like a bacillus or diplococcus in the stage of division. In such cases, the organism may be from 0.5 to 1 micron and with its capsule from 2 to 2.5 microns. In the last stage of division, the germ separates in the capsule and lies at each end like a coccus.

Pardo, in his report of cases, says: "The specific germ is a short capsulated bacillus disposed in chains; it is easily distinguished on account of its capsule; the best stain is Giemsa. Pure cultures were not obtained, although the micro-organism was still present in agar mediums with many other bacteria."

Steele, in his study of the etiologic factor, notes: "Spirilla of a somewhat large size, resembling Spirillum refringcus, were occasionally seen. Sometimes with them, sometimes in their absence, spirochetes identical in their morphologic characteristics with $S$. pallida were found. As this method (scraping) might be open to the objection that these spirochetes might be extraneous agents, removal of the ulcers and smears made from the deeper tissues occasionally showed the presence of these spirochetes; in what percentage of cases they will ultimately appear as constant factors, it is too soon to state. . . . Again another parasite was sometimes in evidence, usually in the fungating. granulating variety of the infection, and often from the enlarged inguinal glands when such are present. Generally seen in large, swollen mononuclear cells, and often in considerable numbers, they possess varying appearances: if for any reason they appear crowded together the bodies resemble enlarged cocci-bacilli, sometimes kidney shaped, not unlike huge gonococci; but when spread out, or in 'spread out' mononuclear cells, there is the appearance of a differentiation into a nucleus, rod-shaped, and a surrounding protoplasm." 
Grindon, among the conclusions arrived at in the study of three cases in the United States says: "The peculiar bodies described by Donovan and Carter are not constantly present in this disease. . . Spirochetes are not constantly present."

\section{REPRCDLCTION OF TIIE DISEASE IN ANIMALS}

Conyers and Daniels' work with guinea-pigs gave negative results. De Beaurefaire Arago and Vianna successfully inoculated cultures in the lower animals, but did not reproduce the disease, as the dogs, guinea-pigs and rats inoculated died within forty-eight hours. Steele treated four monkeys with pieces of tissue removed from various

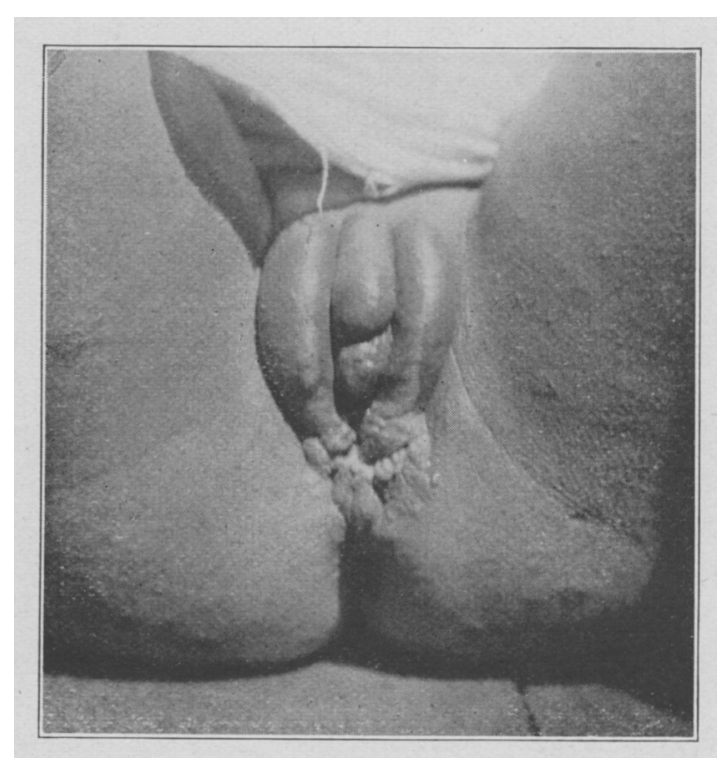

Fig. 3 (Case 3).-A series of lesions varying in size from that of pea to that of bean, on posterior fourchet, with lymph stasis of labia majora, labia minora, prepuce and clitoris.

cases by scarification over the eyebrows and genitals, and in three animals more or less typical lesions appeared over the eyebrows. The three monkeys died within several months.

\section{ASSOCIATED WITH OTHER DISEASES}

All observers are agreed that complications with syphilis occur occasionally. Most authors are positive that ulcerating granuloma is not syphilis. Maitland's observations point to the probability that venereal ulcers may form the point of entrance for the disease. In cases showing marked elephantiasis, the filarial organism has been suspected but it has not been found constantly. 
CONTAGIOUSNESS

Ulcerating granuloma of the pudenda is contagious, but only mildly so. The seat of the ailment on the genitals and the frequency of primary affection of the penis in the male and the vagina in the female combine to indicate a disease of venereal character. Rarely have extragenital cases been reported.

\section{INCLBATION}

Low mentions the case of a white man in whom a small sore appeared on the glans penis two days after cohabitation with a black woman. Maitland's case gave a four-lay incubation period. De Beaurefaire Arago and Vianno report a case of eight days' incubation.

\section{CLINICAL APPEARANCE}

The disease presents itself as a light red, shiny mass of granulation tissue that bleeds easily; the masses are of various sizes, exude a thin, light sanguineous fluid and exhale a fetid odor. The granulations are largest at the margins, the centers appearing rather sunken. The granulations also appear to be strongly developed in the hairy parts of the body. The secretion differs: sometimes it is so great that it runs in drops; in other cases it is scanty, and the masses of granulations are covered with drying scabs. Sometimes the granulomas heal in places by shriveling up, leaving firm, raised, hairless cicatricial tissue with a thin epidermal integument, which is in parts lighter, in parts darker than the skin in the vicinity. Sometimes these cicatrices lie like islands in a mass of granulations; sometimes cicatrization occurs at one side and the disintegrating process advances on the other. In consequence also of cicatricial contraction, the contiguous skin may be drawn away.

OTHER PHYSICAL SIGNS

There is no enlargement of the draining lymph nodes. The lymph channels may, however, become blocked, and pseudlo-elephantiasis of the affected penis or vulva occurs. The growth may invade the urethra in the male and the rectum or vagina in the female. Impassable strictures of the urethra may result, and incurable rectovaginal fistulas are common. The lesion is not invasive, and there are no metastases. The general health is not affected.

In cases affecting the skin or mucous membrane surfaces, there are no subjective symptoms, and the patient does not complain of any discomfort. When the disease advances by continuity or contiguity, and the pathologic process encircles the anus, or invades the urethra, vagina, or rectum, it causes the formation of a cartilaginous stricture. 
Pain on defecation or urination is intense, and is complained of. The stricture may become so obstructive as to prevent the normal functioning of the part.

\section{DLRATION OF THE DISEASE}

The disease is extremely chronic. Complete spontaneous cure is rarely or never observed. The cicatricial tissue that may form soon becomes disintegrated.

\section{DIFFERENTIAL DIAGNOSIS}

To the casual observer, the disease may most often be mistaken for syphilis. It is easily distinguished from the chancre by the history of chronicity, and the absence of lymphatic enlargement. It is differentiated from condylomata lata by the granular appearance, color and ulceration. The slow advance, superficial character and vascularity tend to differentiate the gumma lesion. The serologic reaction may be of help, but will never be conclusive evidence. The inefficiency of antisyphilitic treatment will soon appraise the diagnostician of the mistake of a diagnosis of syphilis.

Yaws is distinguished by the distribution of the condition, and the lack of multiplicity of the lesion.

Tuberculosis is distinguished by the absence of the organism of Koch. The age of the patient, and the character of the lesion will readily exclude the common clinical forms of tuberculosis cutis.

Epithelioma or carcinoma, especially of an early penile lesion, would be diagnosed by the microscopic picture. Clinically, the absence of glandular enlargement and of metastases, the youth of the patient, and the absence of cachexia would exclude malignant disease.

\section{PROPHYLAXIS}

The moral and economic features of the prophylaxis of granuloma pudenda are those of syphilis. Illicit intercourse is usually the mode of transmission. The fact that treatment is almost unavailing would tend to put the victim in the same class as the leper, and require for active prophylaxis the isolation of all persons affected.

\section{TREATMENT}

Antisyphilitic treatment does not affect the disease. Neither salvarsan, mercury, nor potassium iodid alleviate the condition.

The drug recommended is antimony and potassium tartrate (tartar emetic). First advocated by the Brazilians, tartar emetic has taken first place in the treatment of disease. It is used intravenously, and by oral administration.

Intravenously, it is ordinarily given in a concentration of $1: 100$. The solution should be prepared in distilled or redistilled water, and 
in the cold, as heat decomposes the tartar emetic immediately. The dose is 5 c.c. of the $1: 100$ solution, every second day. Ashford writes of increasing the dose gradually to 12 c.c., every second day.

The results with this treatment are not magical. Low gave the patient already mentioned (incubation two days) three injections of salvarsan and thirteen of mercury before giving the tartar emetic. It required $531 / 2$ grains of tartar emetic to effect a complete cure. Pardo noted improvement after the fourth treatment when the ulceration at the groins began to heal, forming a white raised and retracted scar. Cicatrization then took place slowly, and after five months the patient was almost cured; only two areas remained active, one around the anus, and the other around the vaginal orifice. His patient left the hospital and passed from further observation. Ashford expects 12 per cent. of recurrences after tartar emetic cures.

The prescriptions recommended for oral administration are:

1.
R Antimony and potassium tartrate......... gr. iv
Sodium bicarbonate $\ldots \ldots \ldots \ldots \ldots \ldots \ldots \ldots$ gr. $\mathrm{xxx}$

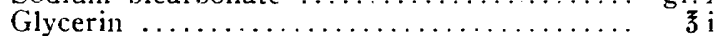
Chloroform water $\ldots \ldots \ldots \ldots \ldots \ldots \ldots \ldots, \ldots \ldots \ldots$
Water.................................. s. ad. $\xi$ ii
M. Sig.: One to two drams in water three times a day.

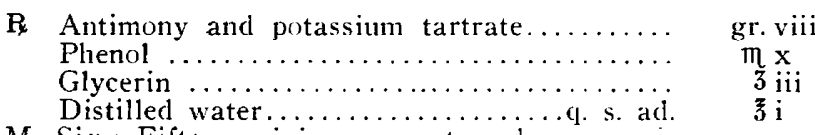
M. Sig.: Fifteen minims every two days.
R Antimony and potassium tartrate........... gr. i
Sodium bicarbonate $\ldots \ldots \ldots \ldots \ldots \ldots \ldots \ldots \ldots, \mathrm{gr} . \mathrm{xv}$

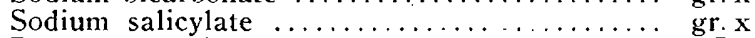

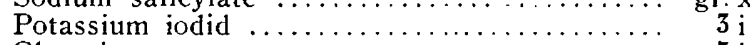

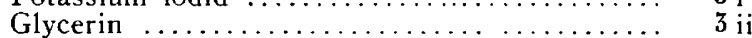
Water............................. s. ad. $\xi_{\mathrm{i}} \mathrm{i}$

2.

3.

M. Sig.: One dram in water, three times a day.

Roentgen rays have been used successfully, but not universally so. Scraping, scarifying, cauterizing, etc., were the local measures of early adoption. Antiseptic lotions and washes to reduce the odor is an agreeable form of symptomatic treatment. Operative measures, such as removing the glans penis because of a stricture caused by the invasion of the process, may be necessary. Early excision of the active growth may be effective. Plastic surgery on cases of long standing is impossible. No operative procedure is feasible once the perineal space of the female is invaded, and the slow but sure advance makes a cloaca. The actual cautery has been advanced by some as being the only means of giving improvement. Most often a combination of all methods is used with varying success. 
SOME OBSERVATIONS ON LLCERATING GRANULCMA OF TIIE PUDENDA AS SEEN ON THE ISLAND OF PORTO RICO

A personal survey of over 12,000 men and 900 women has disclosed four cases of ulcerating granuloma. No case was seen among the soldiers at Camp Las Cases. Two cases were diagnosed in civilian patients at the United States Army Base Hospital, San Juan, and two cases among the women inmates of the hospital jails. Extensive inquiry among the physicians best qualified to know has brought forward no positive statement that the disease has ever been recognized

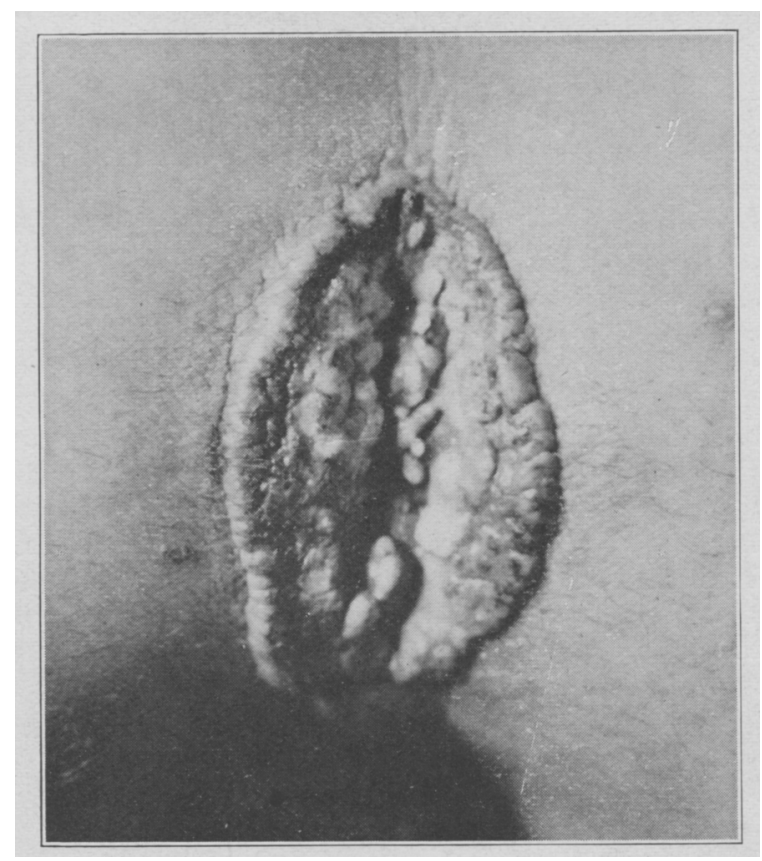

Fig. 4 (Case 4).-A lesion about the anus, showing the raised border, the bright granulations, and the protruding papules.

The indications are, however, that the clisease has been seen, but was never properly diagnosed. It is probable, also, that many of the physicians on the island do not know even the name of the condition.

\section{REPORT CF CASES}

CASE 1.-A negress, aged 22, a prostitute by profession, had had a lesion for nine years which had begun as a small ulcer on the left labium majus and which had extended until for the last few months it had produced much discomfort, especially during evacuation of the bowels.

Condition on Adnission.-The disease process extended between the posterior commissure of the vulva, included the entire perineal space and circumscribed the anus. Internally, it passed into the vagina for $11 \%$ inches; and to 
the internal sphincter of the rectum. The perineal mass was infiltrated, and ulcerations of the mucous surface of the vagina and rectum would ultimately result in a cloaca.

The individual lesions were small papillomas about the size of a pea, and covered with a delicate pink membrane. This membrane reformed within twenty-four hours if removed. The odor was offensive and insistent.

When the patient first came under observation, she presented condylomata lata on the skin surface immediately outside the ulcerated area. The Wassermann reaction was ++++ . Intensive arsphenamin therapy, described below, reduced the Wassermann reaction to negative, cleared the syphilitic manifestations, but the lesions of ulcerating granuloma remained unchanged.

CASE 2.-A man, a mulatto, aged 32, had had a lesion for about three years. which had begun as a small ulcer in the scrotal crural groove. It had extended peripherally, gave discomfort on evacuation of the bowels, and was offensive because of suppuration and foul odor.

Condition on Admission.-The lesions extended from the femoroscrotal sulcus backward in such a way as to encircle the anus; about 2 inches wide on each of the opposing surfaces. The process included the anal mucous membrane as high as the internal sphincter. The growth was covered by a grayish slough. Hairs pierced the lesion. In addition to the main condylomalike lesion, there were individual papules and almond sized lesions in the left femoroscrotal sulcus, and a few lesions as high as the lower margin of the pubic border. The lesions extended deeply into the tissue and were raised above the surface. When cut for biopsy, the fresh surface seemed fibrous and shiny. It bled easily. Within twenty-four hours a new slough had formed over the cut area. The skin of the region was moist, soggy and fissured. The lesion in this patient differed clinically from those in the other two. The mass was much more homogeneous, and the small granulations were not so much in evidence. There appeared to be more surface destruction. Clinically, this case corresponded to those first described by Conyers and Daniels as "lupoid form of so-called groin ulceration."

CASE 3.-A mulatto woman, aged 17 , a prostitute, gave a history of an ulcerative process for two years which had begun as a single lesion, and had advanced slowly.

Condition on Admission.-The patient presented a series of lesions which involved the posterior fourchet, the posterior vaginal wall and the perineal space. The lesions were from pea to bean size, covered with a grayish film, of foul odor, hard and infiltrating. The invasion of the vagina had proceeded for about 2 inches, and gave a distinctly bony hardness. The patient presented marked lymph stasis of the labia majora, labia minora, prepuce and clitoris. The glans clitoris was as large as an adult's glans penis. The glands of the inguinal and femoral regions were not enlarged. When cut for section these lesions were found to be not so hard nor so deep as those of the preceding case.

CASE 4.-A discharged soldier, white, two years hefore had had a small, soft, pendulous, ulcerating papilloma on the intergluteal fold which did not heal. The Wassermann test was negative and local and syphilitic treatment were of no avail. An operation was resorted to, and the lesion was removed. After the operation, which had been performed under a general anesthetic, the patient became disoriented, mildly excitalle and uncontrollable. $\mathrm{He}$ was removed to the local hospital for the insane, where be remaincd for eight months. 
He has been at liberty for over fifteen months, and his present mental condition is fairly good, although he is unable to work.

Condition on Admission.-Extending from the tip of the coccyx to the scrotalperineal junction was a massive lesion of bright granulations. The opposing anal folds were affected and also the mucous membrane of the anus. The border was raised, made up of closely grouped papules covered by a thin grayish membrane, and exuded a serous fluid. The center of the lesion was almost covered with bright red, moist, glistening granulations, with an occasional island of a protruding papule of a white or whitish gray color. Internally, the process encroached on the mucous membrane of the anus. The glands of the groin were not enlarged. There was no lesion of any other part of the body. The Wassermann reaction was negative. When cut for biopsy and tissue smear, the lesion was found to extend deeply into the skin as a hard fibrous mass, which bled profusely.

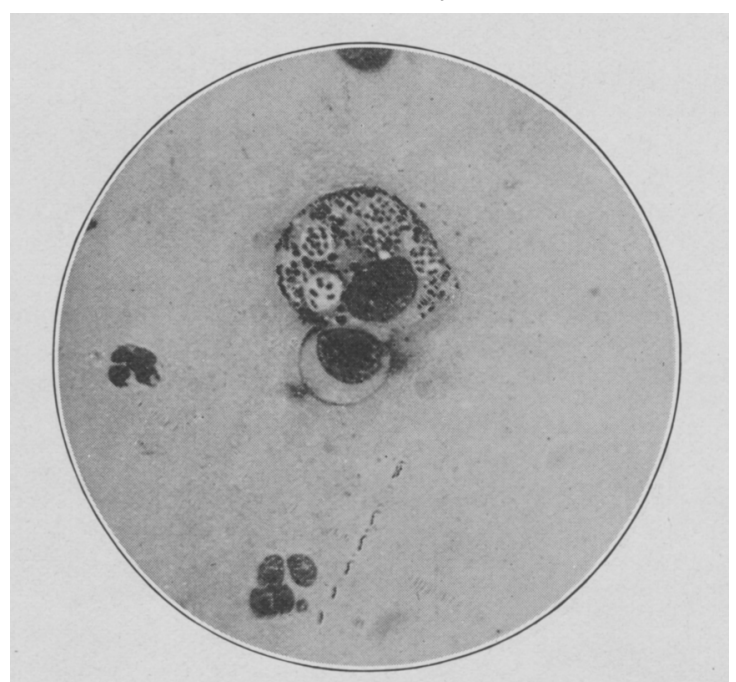

Fig. 5.-Calimatobacterium granulomatis, showing intracellular organisms.

TREATMENT

The first three cases were given antisyphilitic treatment until in Case 1 the condylomata lata disappeared and the WVassermann test became negative, with no change in the appearance of the lesion; and in Cases 2 and 3, until it was seen that the therapentic test was negative. We gave injections of arsenobenzol (Schamberg), neodiarsenol (Canada), and novarsenobenzol (Billon), with no beneficial effect. Mercuric salicylate in grain doses weekly, intramuscularly, was ineffective. The soluble biniodid gave no improvement. Local applications of calomel were tried, both in powder and ointment form, without benefit.

Case 1 improved temporarily under local applications of solutions of potassium permanganate, 1:1,000. Vaginal irrigations of the same drug helped also, especially in reducing the odor. No advance of the lesion was noted during the period of observation. 
Case 2 showed no improvement, except lessened odor after antisyphilitic medication and dressings of calomel ointment. The improvement was due in all probability to enforced cleanliness, rather than to treatment. The patient refused injections of tartar emetic and left the hospital at his own request.

Case 3 received five injections of tartar emetic intravenously, one dose every other day, when she complained bitterly of pain extending into the upper arm and chest. The dose was 5 c.c. of the $1: 100$ solution diluted to 25 c.c. and given by gravity. There was no visible improvement. The thermo-cautery was then used. The results after one week seemed marvelous. The lesion appeared shrunken, the edema of the labia and clitoris had decreased, the odor was diminished,

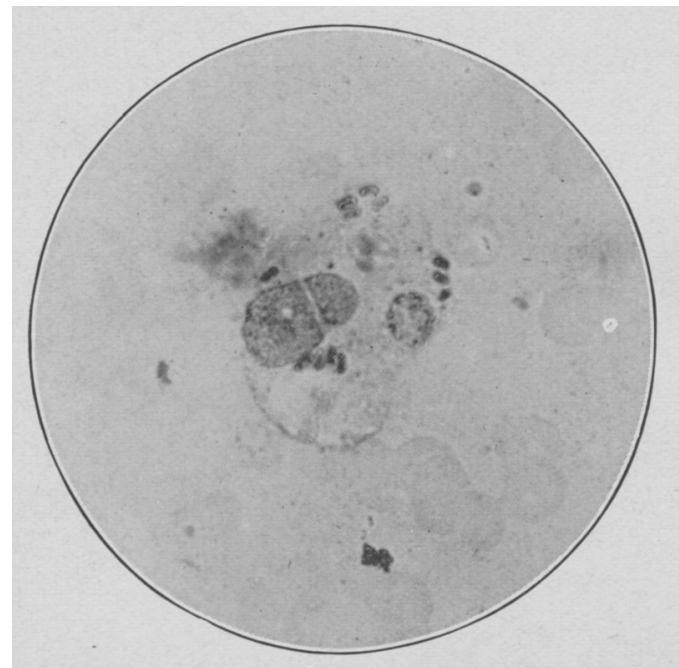

Fig. 6.-Calinatobacterium granulomatis, showing intercellular and extracellular organisms.

the patient was much encouraged and felt better. After the cauterization, local dressings were applied. The thermocautery was then used on the mucous surface which had not been cauterized previously. The indications of prompt recovery did not materialize, however, and within a month most of the lymph stasis had recurred. The patient was then removed to another institution where she is seen at intervals. The lesion has resumed its former appearance. In our opinion, the antimony and potassium tartrate had no part to play in the improvement of this patient. We are fully aware that we cannot judge the efficacy of this form of treatment from this case.

Cases 1 and 3 were in far better general condition after their period of observation than on admission. The improved general health did not affect the local lesions. 
Case 4 has just come under observation. He will receive the antimony and potassium tartrate treatment. From the former sad experience following general anesthesia and the failure of excision of the early growth to prevent extension, it is thought inadvisable to subject this patient to further operative therapy.

\section{BACTERICLOGY ${ }^{1}$}

In each of the four cases, tissue smears were made. The surface of the lesion was well cleansed, and under a local anesthetic a portion of the active nargin was removed. The portion cut was then trimmed so that only deep tissue was available. This was washed in saline

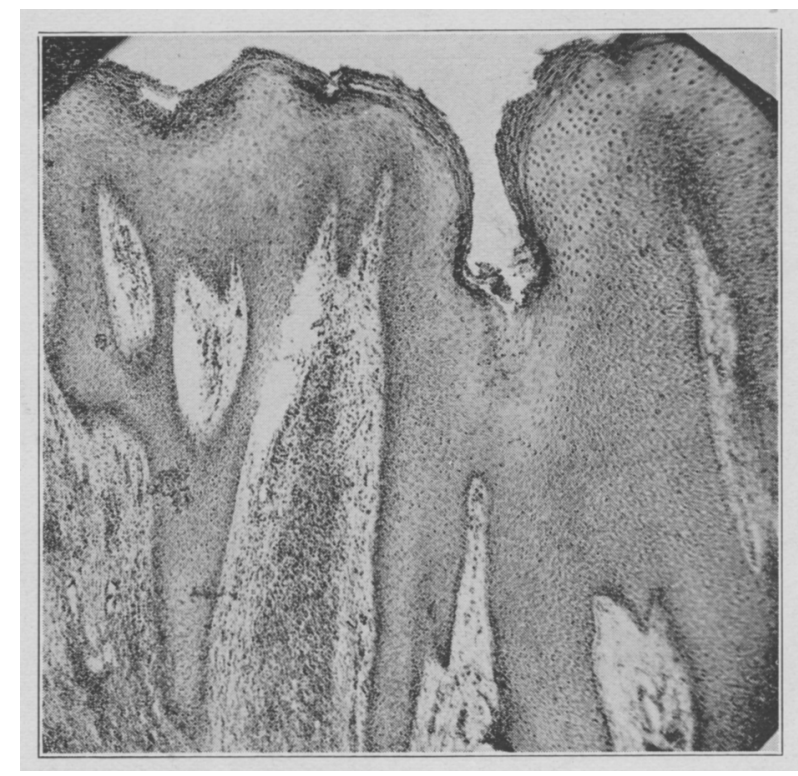

Fig. 7.-Histologic structure in Case 2, showing elongated papillae and interpapillary processes.

solution, expressed, and the smears made. In this manner no superficial containing organisms were present to confuse us.

In Case 1, tissue smears disclosed the spirochetal organism rescribed by $W$ ise and later named $S$. aboriginalis. This spiral organism varies considerably. Some specimens have about four complete turns, irregular in coil, and of varying thickness. It would most likely be confused with $S$. refringens. Another spirochetal form is present which appears more like $S$. pallida. However, it has usually only four

1. The bacteriology is being investigated by Dr. Guiliani of San Juan, Porto Rico, who demonstrated the Calimatobacterium granulomatis for the first time in Porto Rico, after the clinical diagnosis had been established. 
or five turns, the ends are not off the longitudinal axis, and the "saddle" bump is evident in every case. We are certain that this organism is neither $S$. refringons nor $S$. pallida.

Many slides were stained and a thorough search made for other organisms, especially the Calimatobactorium granulomatis, but the search was fruitless.

In Cases 2, 3 and 4, smears made as above indicated disclosed examples of the body described as the Calimatobacterium gramulomatis. The organism was found within large mononuclear cells grouped in a circle of eight or ten organisms. Fach germ was inside its capsule which remained unstained. Each organism was longer than it was

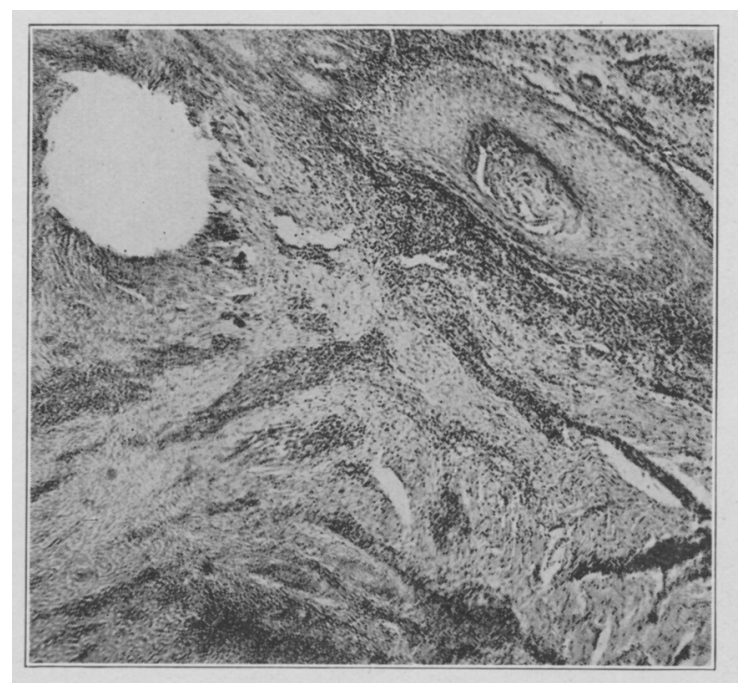

Fig. 8.-Histologic structure in Case 2, showing cellular infiltration and fibrous replacement in cutis.

broad. No nucleus was distinguishable. Extracellular bacteria were also seen which corresponded to the descripttions given by de Souza Araujo. The resemblance to a dividing bacillus or to a diplococcus was marked. These organisms are much smaller than the intracellular type. The relation of the intracellular and extracellular organisms is assumed to be one of adult and immature forms, but this requires further study. In each of the three cases. the extracellular form was found associated with the larger intracellular type. ()casionally, extracellular examples of the large organism were found also.

The examples of Calimatobacterium granulonatis found in Porto Rico are exact duplicates of the organisms pictured in De Bcaurefaire Arago and Vianna's study in the Memoires de Institutte Oswaldo Cruz. 
Cultures were made in Case 3. Tissue blocks from the interior of the lesion were washed in saline solution, rubbed up to form a sort of emulsion, and then planted on various solid and fluid mediums, including Sabouraud's. The cultures were then incubated at 37 C. (98.6 F.). Growth was evident in twenty-four hours. Isolation of the pure culture was difficult, but after the fourth transplant, was successful. The colonies were small, oval, nonliquefying on agar mediums, shiny and very tenacious. Smears made and stained after twenty-four hour's growth disclosed organisms smaller than those usually seen within the mononuclear cells, but larger than the "diplococcus" form. Cultures are still being transplanted, and animal inoculation is contemplated.

\section{IIISTOLOGY}

Cases 1 and 2 were studied histologically. The findings were the same as those transcribed from the histologic studies of Galloway. We have not yet determined the position which the causative organism maintains in the tissue.

SUM MARY

We have diagnosed clinically in Porto Rico, four cases of ulcerating granuloma of the puclenda. In three of these, the Calimatobacterium granulomatis has been demonstrated for the first time in the United States or its dependencies. In one case, the spirochetal organism described by Wise has been observed. We infer that there are two diseases bearing the same name, clinically so similar as to defy differentiation.

The disease is not syphilis, although it may be associated with syphilitic lesions, or be present in a Wassermann positive syphilitic. free of syphilitic manifestations. Salvarsan and mercury are ineffective in its treatment. Antimony and potassium tartrate was not given a sufficiently thorough trial to warrant any positive expression of its efficacy.

The finding of only two cases among 900 prostitutes ( 12 per cent. of whom had active syphilitic manifestations), proves that the danger of infection at the present time in Porto Rico is slight, but should not be entirely disregarded. Quarantine measures should certainly be introduced to prevent the transfer of the infection, especially to our southern ports, either from Porto Rico or from South American countries.

The bacteriologic, histologic and microphotographic studies were made in collaboration with Drs. Gutiérrez, González Martínez and Guiliani at the Institute of Tropical Medicine and Hygiene of Porto Rico. Dr. Guiliani will report at a later date the further studies on the organism isolated from Case 3. 


\section{BIBLIOGRAPHY}

1. British Guinna Medical. Annals

Conyers and Daniels: Lupoid Form of the So-Called "Groin Ulceration" of This Colony 8:13, 1896.

Ozzard: (Title not found) 10:30, 1898 .

Daniels: Granuloma of the Pudenda 10:49, 1898.

Fowler: Perforating Granuloma of the Thigh 11:22, 1899.

Wise: Granuloma Pudenda and Its Parasite 23:54, 1912.

MacLeod: Granuloma Pudenda Tropicum 19:73, 1907.

\section{British Jouknal of Dermatology}

Galloway: Uicerating Granuloma. (Histology) 9:133, 189).

Daniels: Remarks on Ulcerating Granuloma of Pudenda 9:352, 1897.

\section{British Medical Journal}

MacLennan: Memorandum on Observations of Spirochete in Yaws and Granuloma Pudenda 2:995, 1906.

Wise: Note on Etiology of Granuloma Pudenda 1:1274, 1906.

Maitland: Etiology of Granuloma Pudenda 1:1463, 1906.

Castellani: Treatment of Certain Diseases of Protozoal Origin by Tartar Emetic, Either Alone or in Combination 2:552, 1916.

Low and Newman: Case of Ulcerating Granuloma Successfully Treated by Intravenous Injections of Antimony 2:387, 1916.

\section{LANCET}

Maitland: Chronic Venereal Sores or Ulcerating Granuloma, 1899, p. 1624. MacLennan: Spirochetes, 1906, p. 1217. 1910.

Carter: Ulcerative Granuloma of Pudenda. A Protozoal Disease 9:1128,

Steele: An Investigation Into Ulceration Granuloma of the Pudenda as Found in the Government Lock Hospital, Western Australia, 1912, p. 225.

\section{Journal of Tropical Medicine}

Manson: Note on Ulcerating Granuloma of Pudenda, 1899, p. 156.

Renner: Notes on a Case of Ulcerating Granuloma, 1903, p. 139.

Cleland and Hichenloothem: On the Etiology of Ulcerating Granuloma Pudenda, 1909, p. 143.

\section{Indian Medical Gazette}

Maitland: Chronic Venereal Sores, 1898, p. 164.

Williams: Ulcerating Granuloma of Pudenda, 1898, p. 418.

Powell: Sclerotising Granuloma of Pudenda, 1859, p. 167.

\section{Journal of Cutaneous Diseases}

Grindon: Ulcerating Granuloma Tropicum 31:236, 1913.

Pardo: Ulcerating Granuloma of Pudenda 36:206, 1918.

8. Transactions of Royal Soclety of Medicine

Sequeira: Ulcerating Granuloma of Angle of Moutl, 1908, pp. 57 and 92.

9. Transations Society Tropical Medicine and Hygiene

Low: Tartar Emetic in Ulcerating Granuloma 10:37, 1916.

10. Memorias de Institut Oswardo Cruz

Arago and Vianna: Ulcerating Granuloma of the Pudenda 5:211, 1913. 


\section{Amazonas Medico}

Da Matta: Granulomatose (Granuloma ulceroso), 1918, p. 25.

12. Archives Brasileires de Medicina

De Souza Araujo: O Granuloma Venereo na America de Sul 6:111, 1916.

13. Bclletin de La Societe de Pathologie Exotique

Da Matta: Tartar Emetic in Leishmaniasis of the Skin 10:1, 1917.

14. Scheube: Diseases of Warm Countries, Philadelphia, P. Blakiston's Son \& Co., 1903, p. 641.

15. Castellani and Chalmers: Tropical Medicine, Ed. 2, p. 1570.

16. Manson: Tropical Diseases, Ed. 5, New York, Wm. Wood \& Co., 1906, p. 660 .

17. Daniels: Ulcerating Granuloma, in Allbutt and Rolleston: System of Medicine, New York, Macmillan Co. 2:708.

18. Stitt: Diagnostics and Treatment of Tropical Diseases, Philadelphia, P. Blakiston's Son \& Co., 1917, p. 589.

19. Musser and Kelly: Practical Therapeutics. Philadelphia, W. B. Saunders Company 2:723; 5:355.

20. Sequeira: Diseases of the Skin, Philadelphia, P. Blakiston's Son \& Co., 1915, p. 197.

21. Précis de Pathologie Exotique, Le Dantec: Paris, 1905. Jeanselme and Rest: Paris, 1909, p. 514.

22. Salanone Spin: Précis de Pathologie Tropicale, Paris, 1910, p. 691.

\section{Muenchener Medicinische Wochenschrift}

Martine: (Title not found), 1912, No. 14.

24. Archives für Schiffs und Tropen Hygiene

Dempwolff : 1898, p. 283.

Seibert: 1907 , p. 373.

Flu: 1911, Supplement 9.

Seibert : 16: 1912.

Martini : 17: 1913.

25. Goelsel: Chirurgie der Heissen Lände, 1917. 